\title{
Psychoanalytic psychotherapy improves quality of life, depression, anxiety and coping in patients with systemic lupus erythematosus: a controlled randomized clinical trial
}

Céu Tristão Martins Conceição', Ivone Minhoto Meinão', José Atilio Bombana² and Emília Inoue Sato ${ }^{\text {** }}$

\begin{abstract}
Background: Systemic Lupus Erythematosus (SLE) is an autoimmune disease which impairs the quality of life. The objective of study was to evaluate the effectiveness of Brief Group Psychoanalytic Psychotherapy to improve quality of life, depression, anxiety and coping strategies in SLE patients.

Methods: In a randomized clinical trial, 80 female SLE patients were allocated into two groups: therapy group $(n=37)$ and control group $(n=43)$. Therapy group (TG) attended weekly psychotherapy sessions for 20 weeks; control group (CG) remained on a waiting list. Both groups received standard medical care. Questionnaires and scales were applied by blinded evaluators at baseline (T1) and after 20 weeks (T2): Socioeconomic Status, SLE International Collaborating Clinic/American College of Rheumatology-Damage Index, SLE International Disease Activity, SLE Specific Symptom Checklist, SLE Quality of life, Hospital Anxiety Depression Scale, Coping Strategies Inventory. Intent to treat intra- and inter-group analysis was performed for all variables in T1 and T2 using Qui-square, t-Student, Mann-Whitney and Wilcoxon tests. Analysis of Variance was used to compare categorical variables over time. $P<0.05$ was considered significant.

Results: The mean age of patients was 42 years; $54 \%$ were white, with mean disease duration of years 12 . At baseline, both groups were homogeneous in all variables, including medications. After 20 weeks of psychotherapy TG was significantly different from CG, with lower frequency of symptoms $(p=0.001)$, lower level of anxiety $(p=0.019)$ and depression ( $p=0.022)$, better index in five of six domains of quality of life scale $(p \leq 0.005)$, including total SLEQOL $(p<0.001)$ and with higher positive planful problem solving strategy $(p=0.017)$. No change in disease activity score was observed in both groups.
\end{abstract}

Conclusions: Psychoanalytic psychotherapy was effective to improve many domains of quality of life and one positive coping skill and to reduce SLE symptoms, anxiety and depression levels. Brief group psychotherapy can be a useful tool to complement medical care in SLE patients.

Trial registration: Number NCT01840709.

Keywords: Systemic lupus erythematosus, Quality of life, Depression, Anxiety, Coping strategies, Psychoanalytic psychotherapy

\footnotetext{
* Correspondence: eisato@unifesp.edu.br

${ }^{1}$ Rheumatology Division, Escola Paulista de Medicina, Universidade Federal

de São Paulo, Rua Botucatu 740 - Disciplina de Reumatologia CEP 04023900,

São Paulo, SP, Brazil

Full list of author information is available at the end of the article
}

(c) The Author(s). 2019 Open Access This article is distributed under the terms of the Creative Commons Attribution 4.0 International License (http://creativecommons.org/licenses/by/4.0/), which permits unrestricted use, distribution, and reproduction in any medium, provided you give appropriate credit to the original author(s) and the source, provide a link to the Creative Commons license, and indicate if changes were made. The Creative Commons Public Domain Dedication waiver (http://creativecommons.org/publicdomain/zero/1.0/) applies to the data made available in this article, unless otherwise stated. 


\section{Background}

Systemic lupus erythematosus (SLE) is an autoimmune disease that can affect several organs and systems. It is more prevalent in females, mainly in the reproductive period of life and has a multifactorial etiology highlighting genetic predisposition, hormonal, environmental and possible infectious factors [1].

The connection between the limbic system, hypothalamicpituitary-adrenal (HPA) axis and autonomous nervous system has the function to restore body baseline status after exposition to physical or psychological stress [2]. Some authors evaluated the influence of stress as one of the causal factors of SLE and also as a trigger of disease flares $[3,4]$.

Quality of life (QOL) is considered as being healthy, feeling good and being independent and able to work, according to SLE patient reports [5]. SLE patients have poorer functional status than the general population because specific manifestations of SLE that may decrease quality of life $[6,7]$. Feeling of uncertainty about illness, pain and fatigue are important experiences in SLE patients [8], while illness intrusiveness is a stressor that affects QOL [9].

Besides poor QOL in SLE patients, recent studies around the world have shown that anxiety and depression are common symptoms in SLE population. In a systematic review, Palagini et al. found a high variability in the prevalence of depressive disorders in SLE (17-75\%) [10]. The incidence of depression in SLE in the Hopkins Lupus Cohort was 29.7 episodes per 1000 person-years [11]. Neuropsychiatric (NP) manifestations occurred in $47.2 \%$ and mood disorders in $12.7 \%$, with $38.3 \%$ of them attributed to SLE [12]. Ayache and Costa observed prevalence of depression in 65\% of SLE patients in Brazil [13].

Coping concept contains a set of strategies to manage stress, reducing its aversive characteristics and increasing the perception of personal control [14]. The development of coping skills to face SLE disease is very important because manifestations of pain and fatigue besides affections in skin and vital organs are stressful events in patient's lives $[8,9]$. Coping in SLE patients is usually more passive, with the predominance of acceptance strategies [15].

Haija and Shultz had pointed the necessity of an alternative approach to get more adherence to medical treatment in SLE [16] and psychotherapy has been used to supplement clinical care in several diseases, including cancer [17]. There are few studies evaluating the effectiveness of psychotherapy on autoimmune diseases. These studies have shown improvement in coping, quality of life, depression, anxiety, relationship, self-esteem and general health by psychotherapy and psychosocial support in SLE patients [18-20]. However they presented some weakness like small sample sizes $[19,20]$, lack of randomization [19] and positive results only in a few domains [18].

The psychotherapy approach performed in our study comes from psychoanalysis, introduced by Freud to alleviate psychic suffering [21-23]. This approach has been modified over time, in relation to the time of analysis (brief duration), number of participants (group therapy) and different types of diseases began to be treated [24-26]. After Alexander's contributions to psychosomatic medicine [27], Pierre Marty developed an influential psychoanalytic theory based on the concept of mentalization which characterizes the psychosomatic functioning [28]. This concept is similar to alexithymia [29] and patients have difficult to express emotions and deal with them. To these patients, the therapy needs to be more directive, only once a week, face-to-face to access body expression, nominate their feelings and unload instinctual excitations [30].

In the Psychiatric Department of Escola Paulista de Medicina, Universidade Federal de São Paulo, group psychotherapy has been performed to treat somatoform disorders, adapting the psychoanalytic setting to these patients with good results [31,32]. We consider that this approach could also help patients with autoimmune diseases.

Until now, there are no studies in Latin America applying psychotherapy techniques in SLE patients. The objective of this study was to evaluate the effectiveness of brief group psychoanalytic psychotherapy (BGPP) to improve quality of life, anxiety, depression and coping skills in Brazilian SLE patients.

\section{Patients and methods}

A controlled, randomized clinical trial was registered at clinicaltrials.gov (number NCT01840709).

\section{Participants}

Patients were recruited from the Autoimmune Rheumatic Disease outpatient clinic of University Hospital through posters affixed on the outpatient clinic. One hundred and five patients declared interest, however 25 dropped out due to difficulty to fulfill the protocol or presented exclusion criteria. Therefore, a total of 80 female SLE patients were enrolled in the study. Patients were randomized by computer table, receiving an assigned number from 1 to 80 and the secretary informed patients to which group they had been allocated. All patients answered the questionnaires at baseline and after 20 weeks, under the supervision of blind evaluators. The physicians involved in the clinical evaluations were also blinded to the patient allocation group.

Inclusion criteria were: female gender, fulfill American College of Rheumatology (ACR) SLE classification criteria [33], age over 18 years and follow-up at the 
institution for at least 6 months. All patients signed a consent form approved by the institutional ethics committee (protocol 1655/09).

Exclusion criteria were: illiterate, presence of severe mental diseases (severe cognitive deficit, schizophrenia, bipolar disorder, severe depression), physical conditions that could preclude their weekly participation and patients who were receiving psychological treatment or were participating in other protocols.

Inclusion and exclusion criteria were evaluated by the rheumatologists based on patient's current data and medical records. Only one patient (TG) had a history of psychological treatment many years prior.

The therapy group (TG $n=37$ ) was divided into four subgroups, with a maximum of ten patients, according to each patient's preferred schedule (one of four options offered) for psychotherapy attendance. Control group (CG $n=43$ ) remained on a waiting list, only receiving standard medical care according to outpatient clinic schedule. The TG was also continuing to receive usual medical treatment throughout the study.

Four patients dropped out of the study (two on CG and two on TG). In CG, one patient died due to SLE activity and one patient was lost to follow-up. In TG, two patients dropped out of the group, reporting difficulty to participate in the weekly meeting. All patients attended at least 15 of 20 sessions (75\%), except the two dropouts on TG.

\section{Assessment instruments}

Most of the following questionnaires and scales were self-applied with supervision of blinded assessors for some patients with low educational level and difficulty to understand the questions. The clinical evaluations were performed during the medical appointment. Religion and race were self-nominated. All instruments were validated and adapted to the Portuguese language and were applied at baseline (T1) and after 20 weeks (T2), except SLICC score that was applied only at baseline.

1 - ABIPEME Criteria (Associação Brasileira de Institutos de Pesquisa de Mercado) - Socioeconomic questionnaire [34].

The education (years of study) and socioeconomic classification (comfort items at home) are presented in categories.

2 - SLICC/ACR-DI (Systemic Lupus International Collaborating Clinic /American College of Rheumatology - Damage Index) [35].

A measure of the irreversible SLE damage index, present for at least 6 months, evaluating 12 organic systems and calculated by a physician.
3 - SLEDAI (Systemic Lupus Erythematosus International Disease Activity) [36].

A measure of the activity of the disease, scoring each variable of the affected system, evaluated by a physician.

4 - SLE-SSC (Systemic Lupus Erythematosus Specific Symptom Checklist) [37, 38].

A self-related SLE symptom checklist with 38 items evaluating the presence and intensity of several symptoms in the last 30 days. Higher scores indicate worse results.

5 - SLEQOL (Systemic Lupus Erythematosus Quality of Life) $[37,39]$.

A self-related questionnaire with 40 items in 6 domains evaluating the SLE quality of life. The score of each item varies from 0 to 7 and higher scores correspond to poorer quality of life.

6 - HADS (Hospital Anxiety and Depression Scale) $[40,41]$.

A self-administered questionnaire evaluating the domains of anxiety and depression (7 questions by domain). Higher scores indicate higher severity of symptoms.

7 - CSI (Coping Strategies Inventory) [42, 43].

A self-applied questionnaire evaluating coping strategies to deal stressful events with 66 items in 8 domains. Each item can be scored from 0 to 3 . It can measure mature coping, escape/avoidance and aggressiveness strategies.

\section{Intervention}

Intervention was performed in 90-min sessions once a week for 20 weeks for each subgroup. The psychological technique (BGPP) was a short-term (20 weeks) therapy derived from psychoanalysis, which is based in longterm therapy that has been used in the Psychiatric Department of Escola Paulista de Medicina, Universidade Federal de Sao Paulo to treat psychosomatic patients [31, 32]. This technique works according to Marty's model at the Paris School of Psychosomatics [30] and is similar to supportive expressive treatment [44] and to brief dynamic psychotherapy [45], but applied without a manual. The same facilitators managed all the subgroups in this study to guarantee standardization of treatment.

The sessions were organized to achieve the objective to improve the quality of life, coping strategies and emotional balance by the discussion of elected topics. The 
group dynamic was free to enable the emergence of important emotional contents, promoting personal integration and increasing relationships in the group. Coping strategies against life stressors, mainly the disease, were trained during the process. All patients in TG did an evaluation about their experience in the group at the end of study. A therapist, an experienced psychologist in this approach (CTMC) and a co-therapist (IMM), who is also a rheumatologist, conducted the intervention. The therapist coordinated and treated the group. The cotherapist was an observer and recorded the group dialogues, behaviors and emotional expressions. A psychoeducational intervention to clarify patients' doubts about the disease was included in the last session.

\section{Statistical analysis}

The sample size (80 patients) was calculated considering SLEQOL questionnaire, with power of $80 \%$, significance level of $5 \%$ and standard deviation of total SLEQOL of 52 points [37], assuming as significant difference between groups equal to 35 points.

Intra- and inter-group analysis was performed at baseline (T1) and after 20 weeks (T2). Descriptive statistics were used for sample characterization. The proportion of categorical variables was compared using Chi-square test. To compare quantitative variables between groups $t$-Student test was used for those with normal distribution and Mann-Whitney or Wilcoxon test for non-normal distribution. Analysis of variance (ANOVA) test was used to compare categorical variables over time (medication). Medians (minimum-maximum) and means (standard deviation) were used to analyze the data with no normal and normal distribution, respectively. Intent to treat statistical analysis was performed. Statistical Package for the Social Sciences (SPSS), version 17.0 (Chicago, USA) was used for all statistical analysis. $P<0.05$ was considered significant.

\section{Results}

Demographic and socioeconomic data, SLICC/ACR-DI score and medication of 80 SLE patients are shown in Table 1. At baseline, there was no difference concerning age, disease duration, race, years of education, economic class and religion between CG and TG. At baseline, the medications used to control lupus and neuropsychiatric symptoms were similar between groups, with a mean prednisone dosage of $10.38 \mathrm{mg} /$ day. These medications did not vary significantly during the study (data not shown). In general, the SLICC/ACR-DI score was low, without difference between groups (Table 1). The SLEDAI scores were also homogeneous in either the intraor inter-groups analysis. Even if a few patients had presented highly active disease in both groups, the mean level of disease activity was low and comparable between
TG and CG at baseline and at the end of the study (Table 2).

At baseline, both groups were comparable concerning SLE-SSC scores, but TG patients showed significant reduction on frequency and intensity of self-related symptoms after psychotherapy, making the score lower in TG than CG at T2 $(p<0.001)$ (Table 3).

At T2 we observed improvement in the quality of life in TG, by positive changes in five of six domains of SLEQOL scores (occupational activity, symptoms, treatment, humor and self-image) and in the total score $(p<0.001)$, with significant difference comparing with the CG (Table 4).

TG patients showed a significant reduction on anxiety $(p=0.019)$ and depression $(p=0.022)$ levels at T2, which was not observed in CG, highlighting a significant difference between groups at end of study (Table 5).

Concerning CSI, the inter-group analysis at T2 showed significant difference in the planful problem solving skill. However, in the intra-group analysis in TG, positive changes were also observed in other domains (confrontive, escape and avoidance, planful problem solving and positive reappraisal) at the end of the study (Table 6).

\section{Discussion}

This study aimed to test if BGPP technique could improve quality of life and coping skills, as well, reduce anxiety and depression in SLE female patients attended at a tertiary public service in Brazil. The field of this study is the interface between medicine and psychoanalysis using the psychosomatic concepts and techniques as adjunctive help to patients with physical diseases. Psychotherapeutic treatment can lead patients to better coping with illness and increase the adherence to medical treatment [18-20].

We observed significant improvement in symptoms, quality of life, anxiety, depression and in one positive coping domain. The amount and intensity of symptoms on SLE-SSC scale presented significant reduction in patients after psychoanalytic treatment, improving their quality of life and well-being. After treatment, patients handled their body and disease differently, minimizing the importance of symptoms that were felt before as severe and harmful which interfered in their daily activities. However, this improvement did not reflect in disease activity score, as SLEDAI did not have significant reduction, corroborating previous studies using similar techniques [1820], concluding that short-time treatment did not have enough power to modify this score.

Patients of the psychotherapy group presented positive changes in quality of life, with improvement in almost all SLEQOL domains: occupational activities, symptoms, humor, self-image and the way to face medical 
Table 1 Social, demographic and clinical data of SLE patients in control and therapy groups

\begin{tabular}{|c|c|c|c|}
\hline Patients $(n=80)$ & Control $(n=43)$ & Therapy $(n=37)$ & $P$ value \\
\hline Age mean $(S D)^{*}$ & $42.7(11.3)$ & $42.0(12.3)$ & 0.798 \\
\hline Disease duration mean (SD) ${ }^{* *}$ & $11.6(8.2)$ & $12.4(7.8)$ & 0.511 \\
\hline Education $^{\mathrm{a}} \mathrm{n}(\%)^{* * *}$ & & & 0.625 \\
\hline$\leq 3$ years & 05 (11.6) & $03(8.1)$ & \\
\hline $4-8$ years & $16(37.2)$ & $10(27.0)$ & \\
\hline $9-11$ years & 05 (11.6) & $08(21.6)$ & \\
\hline $12-15$ years & $16(37.2)$ & $14(37.8)$ & \\
\hline$\geq 16$ years & $01(2.3)$ & $02(5.4)$ & \\
\hline Socioeconomic class ${ }^{a} n(\%)^{* * *}$ & & & 0.846 \\
\hline $\mathrm{A} / \mathrm{B}$ & $00(.0)$ & $00(.0)$ & \\
\hline$C$ & $26(60.5)$ & $20(54.1)$ & \\
\hline $\mathrm{D}$ & $12(27.9)$ & $12(32.4)$ & \\
\hline E & 05 (11.6) & $05(13.5)$ & \\
\hline Race $n(\%)^{* * *}$ & & & 0.642 \\
\hline White & $22(54.2)$ & $17(45.9)$ & \\
\hline Afro descendants & $21(45.8)$ & $20(54.1)$ & \\
\hline Religion n (\%)*** & & & 0.121 \\
\hline Catholic & $17(39.5)$ & $22(59.5)$ & \\
\hline Evangelic & $13(30.2)$ & $13(35.1)$ & \\
\hline Spiritualist & 05 (11.6) & $01(2.7)$ & \\
\hline Jehovah witness & $04(9.3)$ & $01(2.7)$ & \\
\hline Buddhist & $01(2.3)$ & $00(.0)$ & \\
\hline No religion & $03(7.0)$ & $00(.0)$ & \\
\hline \multicolumn{4}{|l|}{ Lupus medications $\mathrm{n}(\%)^{* * *}$} \\
\hline Azathioprine & $11(25.6)$ & $09(24.3)$ & 0.897 \\
\hline Hydroxychloroquine & $25(58.1)$ & $19(51.4)$ & 0.542 \\
\hline Prednisone & $24(55.8)$ & $21(56.8)$ & 0.932 \\
\hline \multicolumn{4}{|c|}{ Neuropsychiatric medications $n(\%)^{* * *}$} \\
\hline Amitriptyline & $07(16.3)$ & $06(16.2)$ & 0.994 \\
\hline Cyclobenzaprine & $03(7.0)$ & $02(5.4)$ & 0.770 \\
\hline Fluoxetine & 09 (20.9) & $07(18.9)$ & 0.882 \\
\hline SLICC/ACR-DI ${ }^{\mathrm{b}} \mathrm{n}(\%)^{* * *}$ & & & 0.055 \\
\hline Zero & $22(51.2)$ & $11(29.7)$ & \\
\hline 1.00 & $12(27.9)$ & $17(45.9)$ & \\
\hline 2.00 & $06(14.0)$ & $02(5.4)$ & \\
\hline 3.00 & $03(7.0)$ & $04(10.8)$ & \\
\hline 4.00 & $00(.0)$ & $03(8.1)$ & \\
\hline
\end{tabular}

${ }^{a}$ ABIPEME Criteria - Brazilian Association of Market Research Institutes (1995)

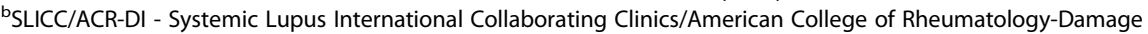
Index (Range: 0-46)

${ }^{*} t$-Student test; ${ }^{* *}$ Mann-Whitney test; ${ }^{* * *}$ Chi-square test

treatment. These results suggest a strong reduction in negative intrusiveness of the disease in treated patient's life, similar to other studies [18-20]. In CG we observed a change in only one SLEQOL domain with worsening of symptoms that likely occurred by chance.
We also found a significant decrease in depression and anxiety levels evaluated by HADS in TG, whereas CG patients did not change. This data revealed the beneficial effects of psychotherapy in their emotional balance. Treated patients began to feel less tense, worried and 
Table 2 Disease activity scores of SLE patients in control and therapy groups over time

\begin{tabular}{lllc}
\hline Time & $\begin{array}{l}\text { Control }(n=43) \\
\text { Median (Min-Max) }\end{array}$ & $\begin{array}{l}\text { Therapy }(n=37) \\
\text { Median (Min-Max) }\end{array}$ & $\begin{array}{l}\text { Inter-group } \\
P^{*}\end{array}$ \\
\hline T1 & $.0(.0-22.0)$ & $2.0(.0-19.0)$ & 0.347 \\
T2 & $.0(.0-20.0)$ & $2.0(.0-21.0)$ & 0.207 \\
Intra-group $P^{* *}$ & 0.925 & 0.214 &
\end{tabular}

SLEDAI Systemic Lupus Erythematosus Disease Activity Index (Range: 0-105) *Mann-Whitney test; **Wilcoxon test

angry. The results are in agreement with Haupt et al. and Navarrete-Navarrete et al. studies [19, 20].

We observed a great improvement in the ability to solve problems but, if we consider the intra-group analyses, changes in four of the eight domains in CSI revealed that psychotherapy improved other coping strategies. These strategies are very important to face daily problems, finding adequate solutions for them and getting enough self-esteem to preserve adequate quality of life. There was a change in the types of coping strategies, trending to face stressors and get emotional balance. Our results are similar to Haupt's study outcomes [19].

At baseline and at the end of the study, the percentage of patients using medications for SLE treatment was similar in both groups and the mean of prednisone dosage used by about $55 \%$ of patients was $10.38 \mathrm{mg} /$ day This medication did not vary significantly during the study. Thus, we do not believe there was a significant influence of the use of prednisone in our results.

Medications for co morbidities, including mild anxiety and depressive symptoms, were also similar between groups at baseline and along the study, reducing the possibility that medications may have contributed to the changes observed in the study. Although severe mental diseases had been excluded, we observed that about $40 \%$ of patients were taking antidepressant drugs, used for fibromyalgia or for mild anxiety and depression symptoms, which are frequently present in SLE patients [1013]. The exclusion of patients with mild psychiatric symptoms could make the study unfeasible, considering the high frequency of these symptoms in SLE patients. Furthermore, previous clinical trials also included

Table 3 Symptom checklist scores of SLE patients in control and therapy groups over time

\begin{tabular}{llll}
\hline Time & Control $(n=43)$ & Therapy $(n=37)$ & $\begin{array}{l}\text { Inter-group } \\
p^{*}\end{array}$ \\
\hline T1 & $52.0(7.0-91.0)$ & $51.0(8.0-119.0)$ & 0.985 \\
$\mathrm{~T} 2$ & $53.0(10.0-99.0)$ & $40.0(2.0-84.0)$ & 0.001 \\
Intra-group $P^{* *}$ & 0.101 & $<0.001$ & \\
\hline $\begin{array}{l}\text { SLE-SSC Systemic Lupus Erythematosus Specific Symptom Checklist } \\
\text { (Range: } 0-152)\end{array}$ \\
$\begin{array}{l}\text { *Mann-Whitney test; } \\
\text { P< } 0.05 \text { significant }\end{array}$
\end{tabular}

patients with depressive and anxiety symptoms and with other mild psychological or psychiatric findings $[19,20]$ and also was using anxiolytic and antidepressant medications [20].

In our study, therapeutic intervention helped patients to lead to positive results in psychological measures through the confidence and support atmosphere established in group dynamic. The therapy technique facilitated the patient's integration, increased feeling of willingness to participate and provided social pressure to encourage patients to report symptoms. So, BGPP helped patients to access deep problems and conflicts with the goal of establishing coping strategies to deal with them. During the sessions, patients elected several themes to discuss, such as anxiety and insecurity related to disease, uncertainty about the future, the possibility of death, depressive reactions about life stressors, lack of emotional control, low self-esteem, interpersonal relationship problems, sexual difficulties and reduced quality of life (due to pain and fatigue) beside personal traumatic issues. Thereby, the group functioned as a support to cope with the disease, allowing each patient to handle their anguish and fears and getting more adaptive forms to face stressors improving the quality of life.

Limitations of the study:

1) Low activity and damage scores - As the most of our patients had low SLEDAI and SLICC/ACR-DI scores, these results cannot be generalized to patients with severe disease. For patients with severe disease, it is recommended continued therapy, according to Parth et al. study [46].

2) Additional generalizations - Because of exclusion criteria in our study, we cannot generalize the results to other populations like male gender, illiterate and patients with high education, high socioeconomic status and severe physical and mental diseases. Patients with no personal demand for psychotherapy are also beyond the scope of this study.

3) A restricted choice of coping scales - At the beginning of the study there was only one coping scale translated and validated to the Portuguese language. This questionnaire was considered too complex and long for the majority of our patients.

4) Placebo effect - We consider the possibility of the improvement obtained to be partly due to the general effect of the intervention (more visits to the outpatient clinic to perform the therapy, the special attention of the therapists and the contact with other patients) and not due to specific psychotherapeutic method. This possibility is related to an inherent feature of psychotherapy, which promotes relationships and provides special care for treated patients. 
Table 4 Quality of life scores of SLE patients in control and therapy groups over time

\begin{tabular}{|c|c|c|c|c|}
\hline \multirow[t]{2}{*}{ Domain } & \multirow[t]{2}{*}{ Time } & \multirow{2}{*}{$\begin{array}{l}\text { Control }(n=43) \\
\text { Median (Min-Max) }\end{array}$} & \multirow{2}{*}{$\begin{array}{l}\text { Therapy }(n=37) \\
\text { Median (Min-Max) }\end{array}$} & \multirow{2}{*}{$\begin{array}{l}\text { Inter-group } \\
p^{*}\end{array}$} \\
\hline & & & & \\
\hline \multirow[t]{3}{*}{ Physical function } & T1 & $12.0(6.0-34.0)$ & $10.0(2.0-39.0)$ & 0.645 \\
\hline & $\mathrm{T} 2$ & $14.0(6.0-36.0)$ & $9.0(6.0-30.0)$ & 0.023 \\
\hline & Intra-group $P^{* *}$ & 0.245 & 0.057 & \\
\hline \multirow[t]{3}{*}{ Occupational activity } & $\mathrm{T} 1$ & $24.0(9.0-59.0)$ & $25.0(1.0-59.0)$ & 0.743 \\
\hline & $\mathrm{T} 2$ & $31.0(9.0-61.0)$ & $17.0(9.0-42.0)$ & 0.001 \\
\hline & Intra-group $P^{* *}$ & 0.055 & 0.001 & \\
\hline \multirow[t]{3}{*}{ Symptoms } & $\mathrm{T} 1$ & $22.0(8.0-49.0)$ & $23.0(6.0-51.0)$ & 0.589 \\
\hline & $\mathrm{T} 2$ & $25.0(8.0-46.0)$ & $14.0(8.0-37.0)$ & 0.001 \\
\hline & Intra-group $P^{* *}$ & 0.023 & $<0.001$ & \\
\hline \multirow[t]{3}{*}{ Treatment } & $\mathrm{T} 1$ & $11.0(4.0-22.0)$ & $10.0(3.0-19.0)$ & 0.591 \\
\hline & $\mathrm{T} 2$ & $11.0(4.0-25.0)$ & $8.0(1.0-20.0)$ & 0.002 \\
\hline & Intra-group $P^{* *}$ & 0.093 & 0.008 & \\
\hline \multirow[t]{3}{*}{ Humor } & $\mathrm{T} 1$ & $14.0(4.0-28.0)$ & $15.0(4.0-28.0)$ & 0.376 \\
\hline & $\mathrm{T} 2$ & $13.0(4.0-28.0)$ & $9.0(4.0-26.0)$ & 0.005 \\
\hline & Intra-group $P^{* *}$ & 0.321 & $<0.001$ & \\
\hline \multirow[t]{3}{*}{ Self-Image } & T1 & $20.0(9.0-51.0)$ & $25.0(9.0-53.0)$ & 0.178 \\
\hline & $\mathrm{T} 2$ & $20.0(9.0-54.0)$ & $15.0(9.0-33.0)$ & 0.003 \\
\hline & Intra-group $P^{* *}$ & 0.764 & $<0.001$ & \\
\hline \multirow[t]{3}{*}{ Total score } & T1 & $114.0(40.0-204.0)$ & $109.0(44.0-226.0)$ & 0.596 \\
\hline & $\mathrm{T} 2$ & $113.0(45.0-236.0)$ & $71.0(40.0-153.0)$ & $<0.001$ \\
\hline & Intra-group $P^{* *}$ & 0.041 & & \\
\hline
\end{tabular}

SLEQOL Systemic Lupus Erythematosus Quality of Life (Range: 40-280)

*Mann-Whitney test; ${ }^{* *}$ Wilcoxon test

$P<0.05$ significant

In addition, we have to admit that this type of intervention only works in patients who have personal demand for psychotherapy. In our study, all patients had such a demand and were motivated to accept psychological help. In this case, we believe that psychoanalytic treatment has been able to offer reception and listening to patients' suffering; it has made possible greater self-knowledge for patients and new ways of facing problems arising from the disease.
The psychotherapy technique used in this study did not follow standard manuals because it was similarly conducted by the same therapists in all subgroups. In case of a replication study, we assumed that therapists with similar experience and training in brief group psychoanalytic psychotherapy attendance could reach similar results.

Our single-center sample was smaller than the Canadian multicenter study [18]. However, it was larger than the

Table 5 Anxiety and depression scores of SLE patients in control and therapy groups over time

\begin{tabular}{lllll}
\hline Domain & Time & Control $(n=43)$ & Therapy $(n=37)$ & $\begin{array}{l}\text { Inter-group } \\
P^{*}\end{array}$ \\
\hline Anxiety & Median (Min-Max) & Median (Min-Max) & 0.340 \\
& T1 & $6.0(1.0-16.0)$ & $9.0(.0-20.0)$ & 0.019 \\
& T2 & $8.0(1.0-18.0)$ & $6.0(1.0-16.0)$ & 0.001 \\
Depression & Intra-group $P^{* *}$ & 0.132 & $8.0(.0-14.0)$ & 0.264 \\
& T1 & $5.0(1.0-16.0)$ & $4.0(.0-14.0)$ & 0.022 \\
& T2 & $7.0(1.0-17.0)$ & $<0.001$ & \\
\hline
\end{tabular}

HADS Hospital Anxiety and Depression Scale (Range: 0-21 by domain)

*Mann-Whitney test; ${ }^{* *}$ Wilcoxon test

$P<0.05$ significant 
Table 6 Coping scores of SLE patients in control and therapy groups over time

\begin{tabular}{|c|c|c|c|c|}
\hline \multirow[t]{2}{*}{ Domain } & \multirow[t]{2}{*}{ Time } & \multirow{2}{*}{$\begin{array}{l}\text { Control }(n=43) \\
\text { Median (Min-Max) }\end{array}$} & \multirow{2}{*}{$\begin{array}{l}\text { Therapy }(n=37) \\
\text { Median (Min-Max) }\end{array}$} & \multirow{2}{*}{$\begin{array}{l}\text { Inter-group } \\
p^{*}\end{array}$} \\
\hline & & & & \\
\hline \multirow[t]{3}{*}{ Confrontive } & $\mathrm{T} 1$ & $0.83(.00-2.33)$ & $1.00(0.33-2.33)$ & 0.217 \\
\hline & $\mathrm{T} 2$ & $1.00(.00-2.33)$ & $0.83(.00-3.00)$ & 0.638 \\
\hline & Intra-group $P^{* *}$ & 0.490 & 0.021 & \\
\hline \multirow[t]{3}{*}{ Distancing } & $\mathrm{T} 1$ & $1.00(0.29-2.14)$ & $1.14(0.14-2.71)$ & 0.698 \\
\hline & $\mathrm{T} 2$ & $0.86(.00-2.00)$ & $0.86(.00-2.29)$ & 0.790 \\
\hline & Intra-group $P^{* *}$ & 0.064 & 0.073 & \\
\hline \multirow[t]{3}{*}{ Self-controlling } & $\mathrm{T} 1$ & $1.40(0.20-3.00)$ & $1.40(0.60-3.00)$ & 0.804 \\
\hline & $\mathrm{T} 2$ & $1.20(.00-2.80)$ & $1.60(0.60-2.40)$ & 0.186 \\
\hline & Intra-group $P^{* *}$ & 0.269 & 0.280 & \\
\hline \multirow[t]{3}{*}{ Seeking social Support } & $\mathrm{T} 1$ & $1.67(0.33-3.00)$ & $1.50(0.33-2.67)$ & 0.292 \\
\hline & $\mathrm{T} 2$ & $1.50(.00-3.00)$ & $1.67(0.17-3.00)$ & 0.520 \\
\hline & Intra-group $P^{* *}$ & 0.109 & 0.385 & \\
\hline \multirow[t]{3}{*}{ Accepting responsibility } & $\mathrm{T} 1$ & $1.71(0.14-2.71)$ & $1.43(0.29-3.00)$ & 0.153 \\
\hline & $\mathrm{T} 2$ & $1.57(.00-2.71)$ & $1.57(0.14-2.71)$ & 0.262 \\
\hline & Intra-group $P^{* *}$ & 0.137 & 0.099 & \\
\hline \multirow[t]{3}{*}{ Escape and Avoidance } & $\mathrm{T} 1$ & $1.50(.00-3.00)$ & $1.50(.00-3.00)$ & 0.554 \\
\hline & $\mathrm{T} 2$ & $1.50(.00-3.00)$ & $1.00(.00-3.50)$ & 0.124 \\
\hline & Intra-group $P^{* *}$ & 0.771 & 0.002 & \\
\hline \multirow[t]{3}{*}{ Planful problem Solving } & $\mathrm{T} 1$ & $1.75(.00-3.00)$ & $1.25(0.50-3.00)$ & 0.748 \\
\hline & $\mathrm{T} 2$ & $1.50(.00-3.00)$ & $2.00(0.75-3.50)$ & 0.017 \\
\hline & Intra-group $P^{* *}$ & 0.411 & $<0.001$ & \\
\hline \multirow[t]{3}{*}{ Positive reappraisal } & $\mathrm{T} 1$ & $1.89(.00-2.89)$ & $1.56(0.22-2.67)$ & 0.218 \\
\hline & $\mathrm{T} 2$ & $1.56(.00-2.78)$ & $1.78(0.39-2.67)$ & 0.063 \\
\hline & Intra-group $P^{* *}$ & 0.061 & 0.002 & \\
\hline
\end{tabular}

CSI Coping Strategies Inventory (Range: $0-3$ by domain)

*Mann-Whitney test; **Wilcoxon test

$P<0.05$ significant

samples of German and Spanish single-center studies $[19,20]$ and reached the estimated sample size to achieve the proposed aims. Concerning age and years of disease duration, our patients had means similar to Edworthy et al. and Navarrete-Navarrete et al. studies $[18,20]$, and all of them had more chronic disease than the patients of Haupt et al. study [19].

We had two drop-outs in each group of the study. The lost patients had the same demographic and clinical characteristics than the long term participants. We believe that, despite the drop-outs, the homogeneity of the groups was maintained. We used intent to treat analysis, repeating the values of the first access.

More psychoanalytic research is needed to clarify the relationship of the immune system and patient's psychological function. Believing that psychological function can be one of the factors that participate as cause and trigger of SLE flares [3, 4], psychotherapeutic support may be useful to supplement clinical and pharmacological treatments in these patients. Psychotherapy group treatment should be offered at specialized centers to treat SLE patients because it can allow cost reduction and emotional benefits for coexistence and exchange of experiences among patients, besides higher effectiveness than individual treatment, according to a systematic review [47].

\section{Conclusion}

In conclusion, BGPP was effective to improve quality of life, including occupational activity, treatment, humor and self-image as well as to reduce symptoms, depression and anxiety levels in SLE patients, besides lead to some positive change in coping strategies. Psychoanalytic psychotherapy can help patients to become stronger to deal with the disease and other important life events, relieving their suffering. 


\section{Abbreviations}

ABIPEME: Associação Brasileira de Institutos de Pesquisa de Mercado; ACR: American College of Rheumatology; ANOVA: Analysis of Variance; BGPP: Brief Group Psychoanalytic Psychotherapy; CG: Control Group; CSI: Coping Strategies Inventory; HADS: Hospital Anxiety and Depression Scale; HPA: Hypothalamic-Pituitary-Adrenal; NP: Neuropsychiatric; QOL: Quality Of Life; SLE: Systemic Lupus Erythematosus; SLEDAI: Systemic Lupus Erythematosus International Disease Activity; SLEQOL: Systemic Lupus Erythematosus Quality of Life; SLE-SSC: Systemic Lupus Erythematosus Specific Symptom Checklist; SLICC/ACR-DI: Systemic Lupus International Collaborating Clinic /American College of Rheumatology - Damage Index; SPSS: Statistical Package for the Social Sciences; T1: Baseline; T2: After 20 weeks; TG: Therapy Group

\section{Acknowledgements}

Sincere thanks to Prof Dr. Sérgio Blay, Prof Dr. Vanessa Cítero, Prof Dr. Valdecir Marvulle for statistical analysis support and Dr. Edgard Torres Reis Neto for SLEDAI and SLICC scores evaluations. Special thanks to psychologists Ermelinda Rodrigues and Marisa Minhoto for the evaluation of patients.

\section{Funding}

The authors declare that there was no funding. All cost was provided by the authors.

\section{Authors' contributions}

CTMC had the idea of study, performed the therapy, wrote the manuscript, analyzed and interpreted psychological data. IMM helped the intervention, analyzed clinical data and contributed with the recruitment of patients. JAB supervised the therapy and EIS supervised all study and both reviewed the manuscript. All authors read and approved the final manuscript.

\section{Ethics approval and consent to participate}

We declare that this study has been performed in accordance with Declaration of Helsinki and was approved by the Research Ethics Committee of the Federal University of São Paulo/São Paulo Hospital (protocol 1655/09) and all participants signed the informed consent form.

\section{Competing interests}

All authors declare that they have no competing interests.

\section{Publisher's Note}

Springer Nature remains neutral with regard to jurisdictional claims in published maps and institutional affiliations.

\section{Author details}

'Rheumatology Division, Escola Paulista de Medicina, Universidade Federal de São Paulo, Rua Botucatu 740 - Disciplina de Reumatologia CEP 04023900 São Paulo, SP, Brazil. 'Department of Psychiatry, Escola Paulista de Medicina, Universidade Federal de São Paulo, São Paulo, Brazil.

\section{Received: 17 September 2018 Accepted: 6 January 2019}

\section{Published online: 22 January 2019}

\section{References}

1. Yazdany J, Dall'Era M. Definitions and classification of lupus and lupusrelated disorders. In: Wallace DJ, Hahn BH, editors. Dubois' Lupus Erythematosus and Related Syndromes. 8th ed. Philadelphia: Elsevier Saunders; 2013. p. 1-7.

2. McEwen BS. Protective and damaging effects of stress mediators. N Engl J Med. 1998;338:171-9.

3. Pawlak CR, Witte T, Heiken H, Hundt M, Schubert J, Wiese B, et al. Flares in patients with systemic lupus erythematosus are associated with daily psychological stress. Psychother Psychosom. 2003;72:159-65.

4. Roussou E, lacovou C, Weerakoon A, Ahmed K. Stress as a trigger of disease flares in SLE. Rheumatol Int. 2013;33:1367-70.

5. Archenholtz B, Burckhardt CS, Segesten K. Quality of life of women with systemic lupus erythematosus or rheumatoid arthritis: domains of importance and dissatisfaction. Qual Life Res. 1999;8:411-6.

6. Thumboo J, Strand V. Health-related quality of life in patients with systemic lupus erythematosus: an update. Ann Acad Med Singap. 2007;36:115-22.
7. Karasz A, Ouellette $S$. Role strain and psychological well-being in women with systemic lupus erythematosus. Women Health. 1995;23:41-5.

8. Wiginton KL. IIIness representations: mapping the experience of lupus. Health Educ Behav. 1999:26:443-53.

9. Devins GM. Illness intrusiveness and the psychosocial impact of lifestyle in chronic life-threatening disease. Adv Ren Repl Ther. 1994;1:251-63.

10. Palagini L, Mosca M, Tani C, Gemignani A, Mauri M, Bombardieri S. Depression and systemic lupus erythematosus: a systematic review. Lupus. 2013;22:409-16

11. Huang $X$, Magder LS, Petri M. Predictors of incident depression in systemic lupus erythematosus. J Rheumatol. 2014;41:1823-33.

12. Hanly JG, Su L, Urowitz MB, Romero-Diaz J, Gordon C, Bae SC, et al. Mood disorders in systemic lupus erythematosus. Arthritis Rheumatol. 2015;67: $1837-47$.

13. Ayache DC, Costa IP. Personality traits and associated changes in women with lupus. Rev Bras Reumatol. 2009;49:643-57.

14. Lazarus RS, Folkman S. Stress, Appraisal and coping. New York: Springer Publishing Company; 1984

15. Rinaldi S, Ghisi M, laccarino L, Zampieri S, Guirardello A, Sarzi-Puttini P, et al. Influence of Coping Skills on Health-Related Quality of Life in Patients With Systemic Lupus Erythematosus. Arthritis Rheum. 2006;55:427-33.

16. Haija AJ, Schulz SW. The role and effect of complementary and alternative medicine in systemic lupus erythematosus. Rheum Dis Clin N Am. 2011:37:47-62.

17. Spiegel D, Morrow GR, Classen C, Raubertas R, Stott PB, Mudaliar N, et al. Group Psychotherapy for recently diagnosed breast cancer patients: a multicenter feasibility study. Psychooncology. 1999;8:482-93.

18. Edworthy SM, Dobkin PL, Clarke AE, Da Costa D, Dritsa M, Fortin PR, et al. Group Psychotherapy Reduces Illness Intrusiveness in Systemic Lupus Erythematosus. J Rheumatol. 2003;30:1011-6.

19. Haupt M, Millen S, Jänner M, Falagan D, Fischer-Betz R, Schneider M. Improvement of coping abilities in patients with systemic lupus erythematosus: a prospective study. Ann Rheum Dis. 2005;64:1618-23.

20. Navarrete-Navarrete N, Peralta-Ramírez MI, Sabio-Sánchez JM, Coín MA, RoblesOrtega $\mathrm{H}$, Hidalgo-Tenorio C, et al. Efficacy of cognitive behavioural therapy for the treatment of chronic stress in patients with lupus erithematosus: a randomized controlled trial. Psychother Psychosom. 2010;79:107-15.

21. Freud S. The handling of dream interpretation in psychoanalysis. In: Strachey J, editor. Standard Edition, vol. 12. London: Hogarth Press; 1958. p. 89-96.

22. Freud S. The dynamics of transference. In: Strachey J, editor. Standard Edition, vol. 12. London: Hogarth Press; 1958. p. 97-108.

23. Freud S. Observations on transference-love. In: Strachey J, editor. Standard Edition, vol. 12. London: Hogarth Press; 1958. p. 157-71.

24. Ferenczi S. Further contribution to the theory and technique of psychoanalysis. London: Hogarth Press; 1950.

25. Rank O. Will Therapy? An Analysis of the Therapeutic Process in Terms of Relationship. New York: A A Knopf; 1936.

26. Bion WR. Experiences in groups and other papers. London: Tavistock Publications; 1961.

27. Alexander F. Psychosomatic medicine. New York: Norton; 1950.

28. Marty P. Mentalisation et psychosomatic. Paris: Delagrange; 1991.

29. Sifneos PE. The prevalence of alexithymic characteristics in psychosomatics patients. Psychother Psychosom. 1973;22:255-62.

30. Marty P. La psychosomatique de l'adulte. Paris: Puf; 1990

31. Bombana JA, Leite ALSS, Miranda CT. How to care for somatizers? Description of a program and summarized case reports. Rev Bras Psiquiatr. 2000;22:180-4.

32. Bombana JA, Abud CC, Prado RA. Assistance and teaching of psychotherapy at the program of treatment and studies of somatization (PAES, UNIFESP). Rev Bras Psicot. 2012;14:34-48.

33. Hochberg MC. Updating the American College of Rheumatology revised criteria for the classification of systemic lupus erythematosus. Arthritis Rheum. 1997:40:1725.

34. Jannuzzi PM, Baeninger R. Qualificação socioeconômica e demográfica das classes da escala Abipeme. Rev Administ. 1996;31:82-90.

35. Gladman D, Ginzler E, Goldsmith C, Fortin P, Liang M, Urowitz M, et al. The development and initial validation of the Systemic Lupus International Collaborating Clinics/American College of Rheumatology damage index for Systemic Lupus Erythematosus. Arthritis Rheum. 1996;39:363-9.

36. Bombardier C, Gladman DD, Urowitz MB, Caron D, Chang CH. Derivation of the SLEDAI - A disease activity index for Lupus patients. Arthritis Rheum. 1992;35:630-40. 
37. Freire EAM, Bruscato A, Ciconelli RM, Leite DRC, Sousa TTS. Translation into Brazilian Portuguese, cultural adaptation and validatation of the systemic lupus erythematosus quality of life questionnaire (SLEQOL). Acta Reumatol Port. 2010;35:334-9.

38. Grootscholten C, Ligtenberg G, Derksen RH, Schreurs KM, de Glas-Vos JW, Hagen EC, et al. Health-related quality of life in patients with systemic lupus erythematosus: development and validation of a lupus specific symptom checklist. Qual Life Res. 2003;12:635-44.

39. Leong KP, Kong KO, Thong BYH, Koh ET, Lian TY, Teh CL, et al. Development and preliminary validation of a systemic lupus erythematosusspecific quality-of-life instrument (SLEQOL). Rheumatology. 2005;44:1267-76.

40. Botega NJ, Bio MR, Zomignani MA, Garcia C Jr, Pereira WAB. Mood disorders among inpatients in ambulatory and validation of the anxiety and depression scale HAD. Rev Saúde Pública. 1995;29:355-63.

41. Zigmond AS, Sanaith RP. The hospital anxiety and depression scale. Acta Psychiat Scand. 1983;67:361-70.

42. Savoia MG, Santana PR, Mejias NP. The adaptation of coping strategies inventory by Folkman and Lazarus in portuguese. Rev Psicol USP. 1996; 183-201.

43. Folkman S, Lazarus RS. If it changes it must be a process: study of emotion and coping during three stages of a college examination. J Pers Soc Psychol. 1985;48:150-70.

44. Luborsky L. Principles of psychoanalytic psychotherapy: a manual for supportive-expressive treatment. New York: Basic Books; 1984.

45. Sifneos PE. Short Term dynamic psychotherapy. Evaluation and Technique. New York: Plenum; 1987.

46. Parth K, Rosar A, Stastka K, Storck T, Loffler-Stastka H. Psychosomatic patients in integrated care: Which treatment mediators do we have to focus on? Bull Menn Clin. 2016;80:326-47.

47. Toseland R, Siporin M. When to recommend group treatment: a review of the clinical and the research literature. Int J Group Psychother. 1986;36:171-201.

Ready to submit your research? Choose BMC and benefit from:

- fast, convenient online submission

- thorough peer review by experienced researchers in your field

- rapid publication on acceptance

- support for research data, including large and complex data types

- gold Open Access which fosters wider collaboration and increased citations

- maximum visibility for your research: over $100 \mathrm{M}$ website views per year

At $\mathrm{BMC}$, research is always in progress.

Learn more biomedcentral.com/submissions 